\title{
A taxonomy of energy resilience ${ }^{1}$
}

\author{
Andrea Gatto ${ }^{2}$ Carlo Drago ${ }^{3}$
}

\begin{abstract}
Resilience is receiving increasing scientific attention, albeit its notion is still in progress and not univocal, especially when it comes to specific sectors such as energy. Energy and resilience policy is detected as a dominant strategy to achieve international development objectives throughout long-term sustainability and wellbeing goals. Energy resilience also crosses major energy policy issues - namely energy vulnerability, security, poverty, and justice. Making use of the Web Of Science 2018 release, this work aims at contributing to a clarification of the concept of energy resilience, proposing a taxonomy. The bibliometric outputs show a sharp increase in scientific publications on the issue. The bibliometric analysis suggests a taxonomy of energy resilience based on 7 approaches or strategies. The results suggest an evolution of the conceptual contributions, that enlarge resilience early use, merely applied to technical and hard sciences. Resilience is today used in different disciplines, including social sciences and sustainability studies, as part of a holistic approach centered on sustainable development.
\end{abstract}

\section{JEL classification: C38 C43 O13 Q48}

Keywords: Energy resilience Taxonomy Bibliometrics Energy policy Sustainable development

\footnotetext{
${ }^{1}$ The authors acknowledge Benjamin Sovacool, Paolo Acampora and two anonymous referees for the useful advice and comments provided.

$2 *$ Corresponding author. Natural Resources Institute, Greenwich University, Central Avenue, Chatham Maritime ME4 4TB, UK. New College of the Humanities at Northeastern University, 19 Bedford Square, Fitzrovia, London WC1B 3HH, UK. Centre for Studies on Europe, Azerbaijan State University of Economics (UNEC), Azerbaijan. Email: a.gatto@gre.ac.uk.

${ }^{3}$ University "Niccolò Cusano" in Rome, Via Don Carlo Gnocchi 3, 00166, Rome, Italy. NCI University London, 4 Selsdon Way Northern \& Shell London E14 9GL UK. Email: carlo.drago@unicusano.it.
} 


\section{Introduction}

\subsection{Modeling resilience: what did we learn?}

The concept of resilience comes from the most renowned notion of one system capacity of recovering, namely "bouncing back" to the original status (Pimm, 1984). This definition was first adopted in engineering, psychiatric and environmental sciences. Overpassing the recovering property, acquired throughout the early interdisciplinary scientific osmosis, the literature that proliferated within the last decade moves a step ahead, introducing the concept of "bouncing forward" (Martin, 2012). This new boundary, corroborated by the EU theory and metric (JRC, 2015), is more in line with our hypothesis of resilience (see also Drago and Gatto, 2017). It also better fits the modern energy policy framework.

Therefore, we see resilience as the adaptive capacity of improving performance, as a result of learning and adaptation, informed by continuous change.

Change shall be conceived in sustainability terms, being applicable for societal, economic and ecological governance (Gatto and Busato, 2019). These indications result paramount for energy and resource policy (International Energy Agency and World Bank, 2017; Gupta, 2008).

\subsubsection{A multidimensional quest}

Resilience is a multifaceted concept. It depends, inter alia, on policymaking (JRC, 2015). The international development agenda foresees a central role for resilience. It appears in multiple goals and targets of sustainable development goals (SDGs). This is the case of social resilience, tailored to climate, shocks and disasters vulnerability of economic, environmental and social nature (targets 1.5 and 13.1); resilient agriculture and food systems (2.4); resilient infrastructures and industrialization (goal 9); urban resilience (11), and resilient maritime ecosystems (14.2) (Agovino et al., 2018; UN, 2015).

Energy is the object of an entire goal itself (SDG 7). Its purpose is to reach, by 2030, an effective, efficient and sustainable energy infrastructure (UN, 2015).

Energy resilience crosses major policy issues - namely energy vulnerability, security, poverty, and justice (Gatto and Busato, 2019). Being a compelling policy quest, there arises the need to measure the complex phenomenon (Drago and Gatto, 2018).

It must be noted that policy is one of the multiple domains pertaining to resilience. tailored dimensions such as personal and social behaviors, social capital, as well as engineering are decisive in the formulation and implementation of resilience. The central point considering energy resilience is the capacity to adapt to the environment by learning. In this context, the policy helps to promote virtuous behaviors, and is part of a broader framework. Resilience must be interpreted through a holistic lens, where sensing, mitigation, and adaptation detect decisive policy pathways, stemming from preparedness, flexibility, and learning capacity.

These cross-cutting features mark a detachment from the former technical conception of resilience-mostly related to resistance in hard sciences or the contraposition between grassroots engineering resilience and ecological resilience (Holling, 1996). 


\section{Methodology design}

Bibliometrics allows investigating the scientific explorations on energy resilience. Our dataset extrapolates 41 publications through the Web Of Science's FN Clarivarate Analytics. The methodology consists of descriptive and exploratory techniques, these are deemed worthy tools to analyze the recent trends in the relevant literature (Aria and Cuccurullo, 2017; Drago and Amidani Aliberti, 2018). Bibliometric analysis outputs are sketched in the Appendix.

\section{Results and discussion}

\subsection{What does bibliometrics tell us?}

As sketched in Fig. 1, 2017 showed a sharp increase in scientific production on energy resilience. Later scholars tackled the issue of energy resilience, attributing interpretations that differ from our work. Our dataset is composed of 41 units. Data regards the timespan 1993-2018. The first two records, which appeared in 1993 and 2002, must be considered outliers: in fact, a continuous scientific production starts from the third article, published in 2008. From 2008 to 2011, solely one paper per year was produced, whilst from 2012 the publication numbers constantly increased year-by-year: from two publications in 2012, to seven in 2016. In 2017, a spike of annual scientific production is registered, consisting of 11 articles. The first part of 2018 displays one publication. This growth shows an increase of interest in the theme of energy resilience from 2012 in the scientific journals. This intensification was probably encouraged by the growing interest in energy resilience all around the world.

The most prolific author is Yamagata (six articles), whereas nine scholars produced two papers. The most cited work is Jameson et al., 1993. The citation number per country shows that the vast majority of papers belong to New Zealand (83 citations), USA (54), Korea (21), Japan (18), England (17), and Romania (14). The most productive countries were USA ( 8 articles), England (4), Indonesia (5), and Japan (4). The citations and the authorships show a relevant bulk of scientific work in the Anglo-Saxon countries and in some East Asian countries - Japan and South Korea above all. These countries show a core in the article production and citation in energy resilience. Major implications come from the keywords used in the dataset papers.

The most used are intuitively energy resilience (11 results) and resilience (10 results). Other main keywords are systems (4 records), biofuel production, urban energy, China, Unites States, security (3 scores), and assessment, bioenergy, energy resilience assessment, energy security, Mullins effect, planning, rebound resilience, behavior, buildings, climate-change, community resilience and energy ( 2 points).

A number of facts emerge. Some papers are strictly related to technical resilience, where the keywords adopted were Mullins effect (engineering), behavior (psychiatrics) or buildings, urban energy, and planning (urban studies). Other works contemplate the early definition of resilience, mentioning the rebound effect. Further publications focus on geography, using "China" and "United States" as keywords. The use of "biofuel production" and "bioenergy" terms show that some works analyze renewable energy sources.

Other articles are associated with techniques or methods, as signaled by the words "assessment" and "energy resilience assessment". The use of climate-change and energy security validates the connection of resilience with social and ecological policy issues. "Systems" refers to the complex nature of the phenomenon and the overall study objective, i.e. energy systems, indicated from the keyword "energy". 


\subsection{A taxonomy proposal}

Overall, the bibliometric methodology allows identifying a relevant taxonomy for energy resilience. The most useful classification can be obtained by considering the keywords extracted and obtained by the text analysis:

1. Resilience in systems: using flexibility and adaptability towards negative effects (Ghisellini et al., 2016; Roege et al., 2014).

2. Approaches to energy resilience which emphasize and explore the concept of assessment and evaluation. The assessment is fundamental in order to provide adequate resilience actions (see Kruyt et al., 2009). These actions should be addressed towards better economic performances and ecological sustainability.

3. Energy resilience approaches which stress the concept of security and analyze possible sources of risk management (see Ang et al., 2015; Winzer, 2012). The diversity in energy supplies and the sustainable resource is a fundamental issue in this context (Jansen and Seebregts, 2010).

4. Urban or regional approaches to energy resilience - where resilience is stressed and based at a spatial level (see Martin, 2012).

5. A community energy resilience approach based on the concrete and active support of the local communities (Scott et al., 2017). The community approach to energy resilience is addressed to balance social values and the environmental impact.

6. An approach to energy resilience based on policies and interventions at national level (as for the use of the keywords "United States" and "China" (see Lin and Bie, 2016).

7. Sectoral approaches to energy resilience (biofuel, bioenergy, etc. See Saha and Eckelman, 2015).

\section{Conclusion and policy implications}

Resilience is an enthralling policy issue by definition, consisting of a feature of adapting by tackling progressive change. This characteristic is due to the capacity of performance improving, that requires to activate a learning and adaptive process based on continuous change. Today, energy and resilience are of primary importance, considering the international development recommendations and the sustainable development goals mandate. They are focal multidimensional concepts, that lead to diverse (energy) policy implications, to be used in a range of cross-boundary disciplines (Gnansounou, 2008).

Exploring the Web Of Science 2018 release, this work proposed a contribution in clarifying the concept of energy resilience. In order to do this, the study ran a bibliometric analysis to draw up an energy resilience taxonomy.

A taxonomy based on 7 approaches to energy resilience was proposed. These diverse interpretations are not exclusive and can contribute each to the cumulative effect. The rationales can be classified in: system implementations; regional approaches; community approaches; national approaches; approaches emphasizing the role of the assessment; approaches stressing the concept of security and call for risk management analyses; sectoral approaches. 


\subsection{Limitations and future research}

As explored previously in the literature, potential limitations in the use of bibliometrics - when applied to scientific papers - arise (Haustein and Lariviére, 2015). A first potential flaw is related to the fact that using bibliometric data implies to consider an extensive analysis of the quality of the data so as to allow a disambiguation of the word sense of the metadata. Another limitation is that bibliometric techniques work on data which are extracted from bibliographic databases only. The bibliometric analysis has examined all the relevant works extracted from the Web Of Science database in 2018 - that is reputed a suitable tool for the bibliometric analysis (Archambault et al., 2006). Works that were not considered are typically non-fullyfledged articles - e.g. non-indexed working papers and white/grey literature. It is not possible using the Web Of Science database to cover the non-English journals. Thus, works on energy resilience written in a language other than English could not be covered in this analysis. However, one would not expect the results to change significantly, seeing as English is the most used language in scientific publications.

Future research would include the bibliometric analysis of different sources - i.e. further databases, working papers, policy papers, and works in languages other than English. Clustering analyses exploiting multivariate techniques, based on text mining, might be worth methodologies for exploring differently groups and classifications. 


\section{References}

Agovino, M., Cerciello, M., Gatto, A., 2018. Policy efficiency in the field of food sustainability. Adjust. Food Agric. Nutr. Index J. Environ. Manag.

Ang, B.W., Choong, W.L., Ng, T.S., 2015. Energy security: definitions, dimensions and indexes. Renew. Sustain. Energy Rev. 42, 1077-1093.

Archambault, E., Vignola-Gagne, E., Cote, G., Larivi, R., 2006. Benchmarking scientific output in the social sciences and humanities: the limits of existing databases. Scientometrics 68 (3), 329-342.

Aria, M., Cuccurullo, C., 2017. bibliometrix: an R-tool for comprehensive science mapping analysis. J. Inf. 11 (4), 959-975 (Elsevier).

Drago, C., Amidani Aliberti, L., 2018. Interlocking directorship networks and gender: a bibliometric analysis. In: Advances in Gender and Culture Studies in Business and Economics. 4th IPAZIA Workshop on Gender Issues, 2018. Springer, Rome, Italy.

Drago, C., Gatto, A., 2017. Modeling and Measuring Energy Resilience. Convegno Nazionale AIQUAV 2017. Qualità della vita e sostenibilità. Florence, Italy.

Drago, C., Gatto, A., 2018. A robust approach to composite indicators exploiting interval data: the Intervalvalued Global Gender Gap Index (IGGGI). In: Advances in Gender and Culture Studies in Business and Economics. 4th IPAZIA Workshop on Gender Issues, 2018. Springer, Rome, Italy.

Gatto, A., Busato, F., 2019. Energy vulnerability around the world: The global energy vulnerability index (GEVI). Journal of Cleaner Production. https://doi.org/10.1016/j.jclepro.2019.118691. https://www.sciencedirect.com/science/article/pii/S0959652619335619?via\%3Dihub.

Ghisellini, P., Cialani, C., Ulgiati, S., 2016. A review on circular economy: the expected transition to a balanced interplay of environmental and economic systems. J. Clean. Prod. 114, 11-32.

Gnansounou, E., 2008. Assessing the energy vulnerability: case of industrialised countries. Energy Policy 36 (10), 3734-3744.

Google Trends, 2019. Source of data: Google Trends. https://www.google.com/trends. (Accessed 22 June 2019).

Google, 2019. How Trend Works. https://newsinitiative.withgoogle.com/training/lesso n/4876819719258112?image1/4trends\&tool1\%/4Google\%20Trends. (Accessed 8 July 2019).

Gupta, E., 2008. Oil vulnerability index of oil-importing countries. Energy Policy 36 (3), 1195-1211.

Haustein, S., Lariviére, V., 2015. The use of bibliometrics for assessing research: possibilities, limitations and adverse effects. In: Incentives and Performance. Springer, Cham, pp. 121-139.

Holling, C., 1996. Engineering versus ecological resilience. In: Engineering within Ecological Constraints. National Academy of Engineering, ISBN 0-309-59647-5.

International Energy Agency and World Bank, 2017. Sustainable Energy for All 2017- Progress toward Sustainable Energy. World Bank, Washington DC. 
Jameson, M.W., Hood, J.A., Tidmarsh, B.G., 1993. The effects of dehydration and rehydration on some mechanical properties of human dentine. Journal of biomechanics 26 (9), 1055-1065.

Jansen, J.C., Seebregts, A.J., 2010. Long-term energy services security: what is it and how can it be measured and valued? Energy Policy 38 (4), 1654-1664.

JRC, 2015. The Challenge of Resilience in a Globalized World.

Kruyt, B., van Vuuren, D.P., De Vries, H.J.M., Groenenberg, H., 2009. Indicators for energy security. Energy Policy 37 (6), 2166-2181.

Lin, Y., Bie, Z., 2016. Study on the resilience of the integrated energy system. Energy Procedia 103, 171176.

Martin, Ron, 2012. Regional economic resilience, hysteresis and recessionary shocks. J. Econ. Geogr. 12 (1), $1-32$.

Pimm, Stuart L., 1984. The complexity and stability of ecosystems. Nature 307 (5949), 321-326.

Roege, P.E., Collier, Z.A., Mancillas, J., McDonagh, J.A., Linkov, I., 2014. Metrics for energy resilience. Energy Policy 72, 249-256.

Saha, M., Eckelman, M.J., 2015. Geospatial assessment of potential bioenergy crop production on urban marginal land. Appl. Energy 159, 540-547.

Scott, A., Worrall, L., Hornberg, J., To, L.S., 2017. How Solar Household Systems Contribute to Resilience. Overseas Development Institute, London.

UN, RES/70/1, 2015. Transforming Our World: the 2030 Agenda for Sustainable Development.

Winzer, C., 2012. Conceptualizing energy security. Energy Policy 46, 36-48. 
Appendix: Bibliometric analysis

\section{A - Main Bibliometric Results}

\section{A.1) Main Information about data}

Articles

41

Sources (Journals, Books, etc.)

37

Keywords Plus (ID)

105

Author's Keywords (DE)

139

Period

$1993-2018$

Average citations per article

5.756

Authors

124

Author Appearances

146

Authors of single authored articles

2

Authors of multi authored articles

122

Articles per Author

0.331

Authors per Article

3.02

Co-Authors per Articles 
A.2) Annual Scientific Production

Year Articles

$1993 \quad 1$

$2002 \quad 1$

$2008 \quad 1$

$2009 \quad 1$

$2010 \quad 1$

$2011 \quad 1$

$2012 \quad 2$

20133

20145

$2015 \quad 6$

$2016 \quad 7$

$2017 \quad 11$

$2018 \quad 1$ 
Annual Percentage Growth Rate 0

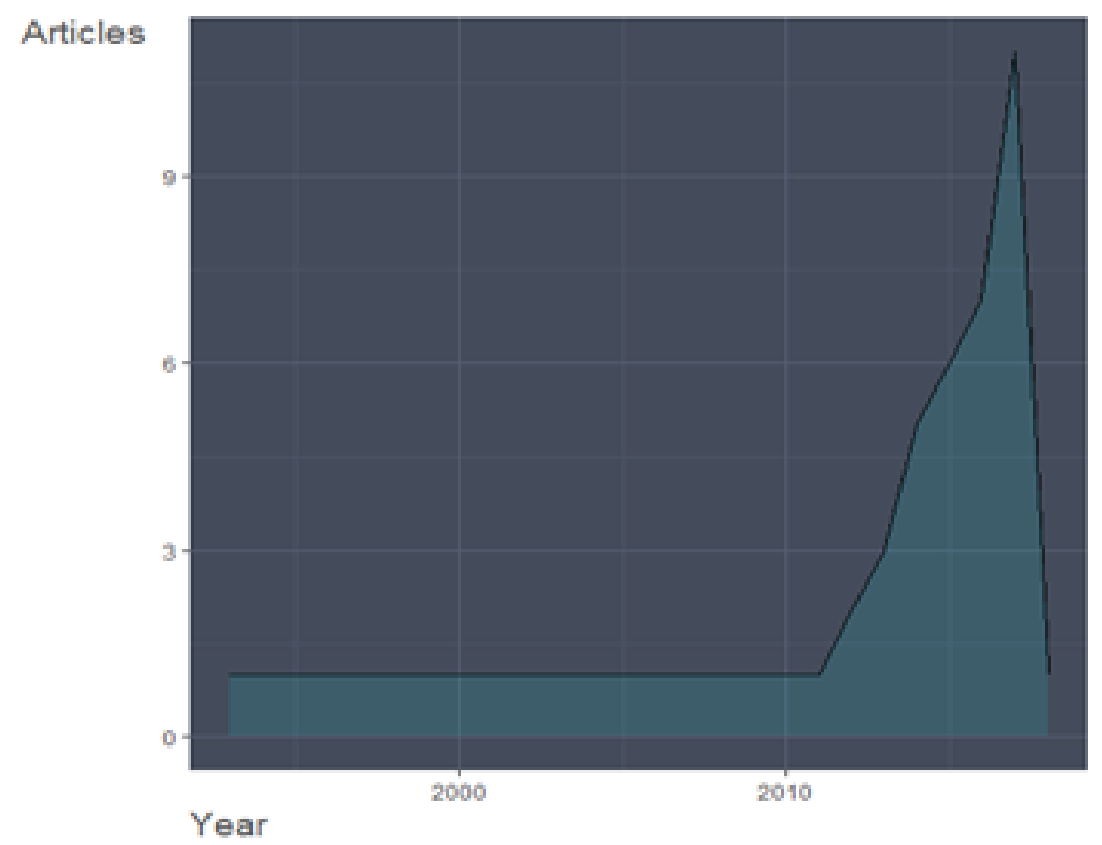

Fig. 1 Annual Scientific Production

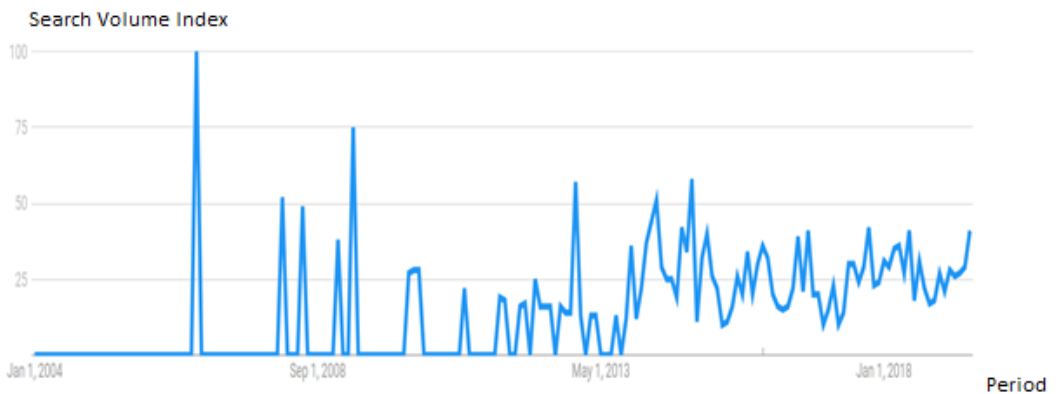

Fig. 2 - Interest over time: Google query "energy resilience"

The Search Volume index is computed by normalizing the different absolute values on the searches on “energy resilience" presented on a scale 0-100 (Google 2019)

\section{A.3) Most Productive Authors}


Authors

1 YAMAGATA Y

2 AOKI K

3 CIOBANU C

4 DOROHOI DO

2

ECKELMAN MJ

5 ECKELMAN MJ

6 ERKER S

2 SAHA M

7 HERDIANSYAH H 2 SHARIFI A

8 KINDERMANN G 2 CIOBANU C

9 KRAXNER F

10 LEDUC S
1.000

Articles Fractionalized

1.652

1.250

1.000

1.000

1.000

1.000

0.667

0.667

0.667

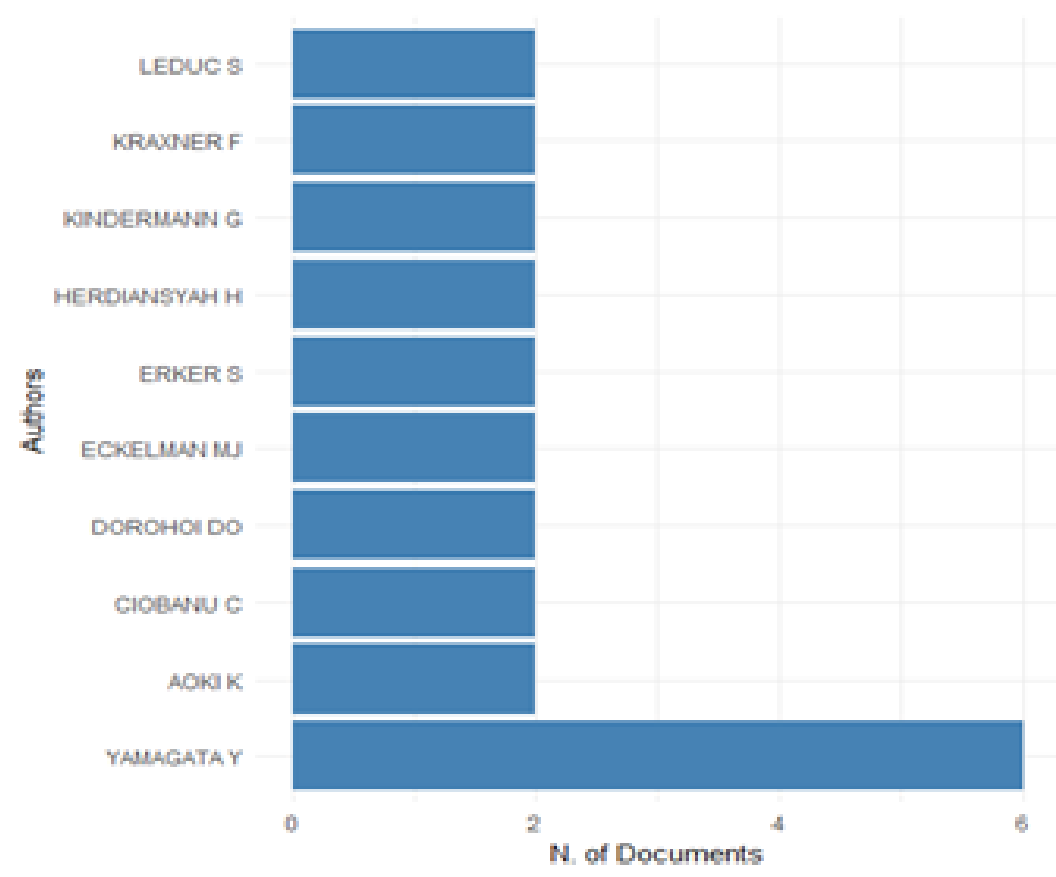

Fig. 3. Authors by number of documents 


\section{A.4) Top manuscripts per citations}

Paper

1 JAMESON MW;HOOD JAA;TIDMARSH BG,(1993),J. BIOMECH.

2 ROEGE PE;COLLIER ZA;MANCILLAS J;MCDONAGH JA;LINKOV I,(2014),ENERGY POLICY

3 KWON JS;LEE YK;LIM BS;LIM YK,(2008),AM. J. ORTHOD. DENTOFAC. ORTHOP.

4 NECHIFOR CD;DOROHOI DO;CIOBANU C,(2009),ROM. J. PHYS.

5 SAHA M;ECKELMAN MJ,(2015),APPL. ENERGY

6 AFGAN N;VEZIROGLU A,(2012),INT. J. HYDROG. ENERGY

7 SHARIFI A;YAMAGATA Y,(2016),RENEW. SUST. ENERG. REV.

8 SIRCAR I;SAGE D;GOODIER C;FUSSEY P;DAINTY A,(2013),FUTURES

9 HE P;NG TS;SU B,(2015),ENERGY ECON.

10 GHASEMIEH H;HAVERKORT BR;JONGERDEN MR;REMKE A,(2015),2015 45TH ANNUAL IEEE/IFIP INTERNATIONAL CONFERENCE ON DEPENDABLE SYSTEMS AND NETWORKS

TC TCperYear

$177 \quad 3.08$

$226 \quad 6.50$

$318 \quad 1.80$

$414 \quad 1.56$ 

$\begin{array}{lll}5 & 13 & 4.33\end{array}$
$\begin{array}{lll}6 & 12 & 2.00\end{array}$
$\begin{array}{lll}7 & 11 & 5.50\end{array}$
$\begin{array}{lll}8 & 7 & 1.40\end{array}$
$\begin{array}{lll}9 & 6 & 2.00\end{array}$
$106 \quad 2.00$

A.5) Most Productive Countries (as for corresponding authors)

$\begin{array}{lccc}\text { Country } & \text { Articles } & \text { Freq } & \text { SCP MCP } \\ 1 \text { USA } & 80.1951 & 7 & 1 \\ 2 \text { ENGLAND } & 50.1220 & 4 & 1 \\ 3 \text { INDONESIA } & 50.1220 & 5 & 0 \\ 4 \text { JAPAN } & 50.1220 & 4 & 1 \\ 5 \text { AUSTRIA } & 40.0976 & 2 & 2 \\ 6 \text { CHINA } & 20.0488 & 2 & 0 \\ 7 \text { KOREA } & 20.0488 & 1 & 1 \\ 8 \text { NEW ZEALAND } & 20.0488 & 2 & 0 \\ 9 \text { ROMANIA } & 20.0488 & 2 & 0\end{array}$


10 AUSTRALIA $\quad 10.0244 \quad 1 \quad 0$

SCP: Single Country Publications

MCP: Multiple Country Publications

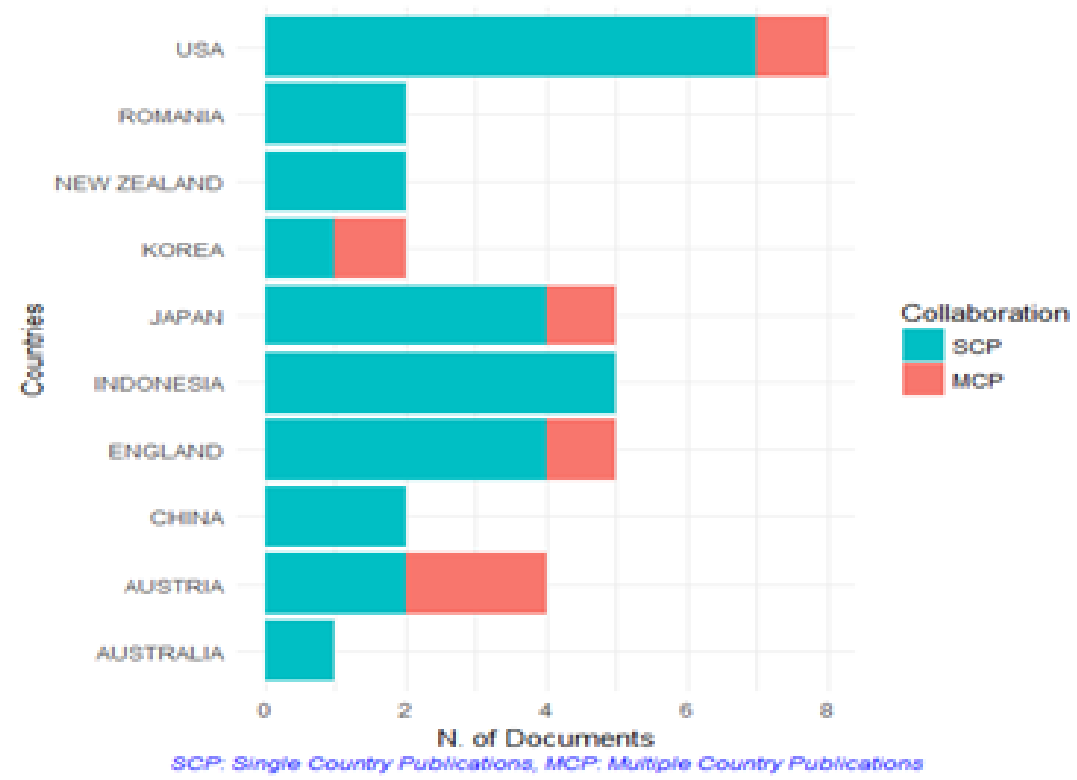

Fig. 4 Most productive countries

\section{A.6) Total Citations per Country}

Country Total Citations $\quad$ Average Article Citations

1 NEW ZEALAND

83

41.50

2 USA 
3 KOREA

4 JAPAN

3.60

5 ENGLAND

17

3.40

6 ROMANIA

14

7.00

7 AUSTRIA

8 AUSTRALIA

6

6.00

9 NETHERLANDS

6

6.00

10 SINGAPORE

6

6.00

\section{A.7) Most Relevant Sources}

Sources

1 5TH INTERNATIONAL CONFERENCES ON GEOLOGICAL GEOGRAPHICAL AEROSPACES AND EARTH SCIENCES 2017 (5TH AEROEARTH 2017)

2 APPLIED ENERGY

3 ENERGY POLICY

4 JOURNAL OF CLEANER PRODUCTION

52013 15TH INTERNATIONAL CONFERENCE ON TRANSPARENT OPTICAL NETWORKS (ICTON 2013)

62014 IEEE INTERNATIONAL ELECTRIC VEHICLE CONFERENCE (IEVC) 
72015 45TH ANNUAL IEEE/IFIP INTERNATIONAL CONFERENCE ON DEPENDABLE SYSTEMS AND NETWORKS

8 8TH INTERNATIONAL CONFERENCE ON APPLIED ENERGY (ICAE2016)

9 8TH INTERNATIONAL CONFERENCE ON SUSTAINABILITY IN ENERGY AND BUILDINGS SEB-16

10 ACTA METALLURGICA SINICA

Articles

12

$2 \quad 2$

32

42

$5 \quad 1$

$6 \quad 1$

$7 \quad 1$

$8 \quad 1$

$9 \quad 1$

$10 \quad 1$ 
A.8) Most Relevant Keywords

Author Keywords (DE) Articles Keywords-Plus (ID) Articles

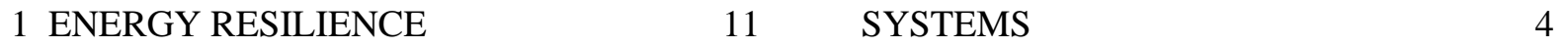

2 RESILIENCE

10 BIOFUEL PRODUCTION

3 URBAN ENERGY

3 CHINA

4 ASSESSMENT

2 SECURITY

5 BIOENERGY

2 UNITED-STATES

3

6 ENERGY RESILIENCE ASSESSMENT

2 BEHAVIOR

7 ENERGY SECURITY

2 BUILDINGS

8 MULLINS EFFECT

2 CLIMATE-CHANGE

9 PLANNING

2 COMMUNITY RESILIENCE

10 REBOUND RESILIENCE

2 ENERGY

\section{A.9) Dominance Factor Multi Authored First Authored Rank by Articles}

$\begin{array}{lcccc}\text { ERKER S } & 1.0000000 & 2 & 2 & 2 \\ \text { KRAXNER F } & 1.0000000 & 2 & 2 & 3 \\ \text { NECHIFOR CD } & 1.0000000 & 2 & 2 & 5 \\ \text { SAHA M } & 1.0000000 & 2 & 2 & 6 \\ \text { SHARIFI A } & 1.0000000 & 2 & 2 & 7\end{array}$




$\begin{array}{lcccc}\text { ABODEELY JM } & 1.0000000 & 1 & 1 & 8 \\ \text { AFGAN N } & 1.0000000 & 1 & 1 & 9 \\ \text { CHAN D } & 1.0000000 & 1 & 1 & 10 \\ \text { LUO RK } & 0.5000000 & 2 & 1 & 4 \\ \text { YAMAGATA Y } & 0.1666667 & 6 & 1 & 1\end{array}$

Rank by DF

ERKER S 1

KRAXNER F 2

NECHIFOR CD 3

SAHA M 4

SHARIFI A 5

ABODEELY JM 6

$\begin{array}{ll}\text { AFGAN N } & 7\end{array}$

$\begin{array}{ll}\text { CHAN D } & 8\end{array}$

LUO RK 9

YAMAGATA Y 10 